Article

\title{
A NAC Transcription Factor TuNAC69 Contributes to ANK-NLR-WRKY NLR-Mediated Stripe Rust Resistance in the Diploid Wheat Triticum urartu
}

\author{
Yang Xu ${ }^{1}\left(\mathbb{D}\right.$, Shenghao Zou ${ }^{1}$, Hao Zeng ${ }^{1}$, Wei Wang ${ }^{1}\left(\mathbb{D}\right.$, Bin Wang ${ }^{2}$, Huan Wang ${ }^{3, *}$ and Dingzhong Tang ${ }^{1, * \mathbb{D}}$ \\ 1 State Key Laboratory of Ecological Control of Fujian-Taiwan Crop Pests, Key Laboratory of Ministry of \\ Education for Genetics, Breeding and Multiple Utilization of Crops, Plant Immunity Center, Fujian \\ Agriculture and Forestry University, Fuzhou 350002, China; xuyang@fafu.edu.cn (Y.X.); \\ shenghao_zou@126.com (S.Z.); biozengh@163.com (H.Z.); wangwei@fafu.edu.cn (W.W.) \\ 2 College of Life Science, Fujian Agriculture and Forestry University, Fuzhou 350002, China; \\ wangbin_doc@163.com \\ 3 College of Agronomy, State Key Laboratory of Wheat and Maize Crop Science, and Center for Crop Genome \\ Engineering, Longzi Lake Campus, Henan Agricultural University, Zhengzhou 450046, China \\ * Correspondence: hwang@henau.edu.cn (H.W.); dztang@fafu.edu.cn (D.T.)
}

check for

updates

Citation: Xu, Y.; Zou, S.; Zeng, H.; Wang, W.; Wang, B.; Wang, H.; Tang, D. A NAC Transcription Factor TuNAC69 Contributes to ANK-NLR-WRKY NLR-Mediated Stripe Rust Resistance in the Diploid Wheat Triticum urartu. Int. J. Mol. Sci. 2022, 23, 564. https://doi.org/ 10.3390/ijms23010564

Academic Editors: Hari B. Krishnan and Yangrong Cao

Received: 9 December 2021

Accepted: 1 January 2022

Published: 5 January 2022

Publisher's Note: MDPI stays neutral with regard to jurisdictional claims in published maps and institutional affiliations.

Copyright: (c) 2022 by the authors. Licensee MDPI, Basel, Switzerland. This article is an open access article distributed under the terms and conditions of the Creative Commons Attribution (CC BY) license (https:// creativecommons.org/licenses/by/ $4.0 /)$.

\begin{abstract}
Stripe rust is one of the most devastating diseases in wheat. Nucleotide-binding site (NBS) and leucine-rich repeat (LRR) domain receptors (NLRs) recognize pathogenic effectors and trigger plant immunity. We previously identified a unique NLR protein YrU1 in the diploid wheat Triticum urartu, which contains an N-terminal ANK domain and a C-terminal WRKY domain and confers disease resistance to stripe rust fungus Puccinia striiformis f. sp. Tritici (Pst). However, how YrU1 functions in disease resistance is not clear. In this study, through the RNA-seq analysis, we found that the expression of a NAC member TuNAC69 was significantly up-regulated after inoculation with Pst in the presence of YrU1. TuNAC69 was mainly localized in the nucleus and showed transcriptional activation in yeast. Knockdown TuNAC69 in diploid wheat Triticum urartu PI428309 that contains YrU1 by virus-induced gene silencing reduced the resistance to stripe rust. In addition, overexpression of TuNAC69 in Arabidopsis enhanced the resistance to powdery mildew Golovinomyces cichoracearum. In summary, our study indicates that TuNAC69 participates in the immune response mediated by NLR protein YrU1, and likely plays an important role in disease resistance to other pathogens.
\end{abstract}

Keywords: NLR; YrU1; TuNAC69; stripe rust; plant immunity

\section{Introduction}

Stripe rust, caused by Puccinia striiformis f. sp. tritici (Pst), is one of the most devastating diseases of crops that poses a major threat to the production of hexaploid wheat (Triticum aestivum L.), around the world [1,2]. To date, in the effort to fight for wheat stripe rust, several stripe rust resistance genes have been identified and cloned, including $Y r 5 / Y r 7$, YrSP, Yr15, Yr18/Lr34, Yr36, Yr46, YrAS2388 and YrU1 [3-8]. Among these, YrAS2388 encodes a nucleotide-binding site (NBS) and leucine-rich repeat (LRR) proteins (NLRs), and $Y r 5 / Y r 7$ and $Y r S P$ encode NLR with an additional BED domain [9]. YrU1 encodes an NLR, with an N-terminal ankyrin-repeat and a C-terminal WRKY domain, which exists only in Triticum species, representing a very unique structure in plants [8]. The wheat stripe resistances mediated by those NLRs are race-specific and are generally only effective against a subset of Pst isolates.

Plant NLRs recognize pathogenic effectors and lead to effector-triggered immunity (ETI) $[10,11]$. The expression of many defense-related genes are up-regulated in ETI, indicating that transcription factors play key roles in this process. Although some reports show that plant NLRs can directly interact with transcription factors, how NLRs regulate defense responses dynamically by transcription factors is still unclear [12-14]. 
The NAC (NAM, ATAF1/2 and CUC2) transcription factor family is one of plantspecific transcription factor families [15]. The first member of the NAC transcription factor family, PhNAM (No apical meristem), was cloned from Petunia hybrid. PhNAM plays a role in the formation and differentiation of apical meristem of Petunia hybrid [16]. Subsequently, more members of the NAC family were cloned, such as CUC (Cup-shaped cotyledon) [17]. Some NAC members are found to play an important role in plant immunity. For instance, Arabidopsis ATAF1 plays a negative role in disease resistance. The Arabidopsis ataf1 mutants are more resistant to Pseudomonas syringae pv. tomato DC3000 and Botrytis cinerea, while Arabidopsis overexpression ATAF1 plants are more susceptible to Botrytis cinerea [18]. The Arabidopsis anac019 anac055 mutants display enhanced resistance to Botrytis cinerea, while overexpressing ANAC019 or ANAC055 led to reduced resistance to Botrytis cinerea $[19,20]$. In barley, transient overexpression of $\mathrm{HvNAC6}$ can improve the penetration resistance to powdery mildew fungus [21]. In wheat, TaNACL-D1 and TaFROG enhanced the resistance of wheat to Fusarium graminearum [22]. In contrast, TaNAC30, TaNAC21/22 and TaNAC35 play a negative regulatory role in wheat resistance to stripe rust and leaf rust [23-25]. However, there is very little information about whether NAC transcription factors directly participate in NLR-mediated resistance in plants.

The diploid wheat species Triticum urartu is the progenitor species of the A genome of bread wheat. Previously, we identified a stripe rust resistant NLR protein YrU1 and a powdery mildew resistance NLR protein Pm60 in T. urartu accession PI428309 [8,26]. In this study, we found that the expression level of TuNAC69 increased significantly in RNA-seq analysis in PI428309 upon stripe rust infection. Stripe rust resistance, but not powdery mildew resistance, was reduced in PI428309 by knocking down the TuNAC69 by barley stripe mosaic virus (BSMV)-induced gene silencing (VIGS), indicating that TuNAC69 participates in the immune response mediated by YrU1. In addition, the penetration resistance of wheat to powdery mildew fungus was increased by overexpression of TuNAC69 in single-cell assays. Furthermore, overexpression of TuNA69 in Arabidopsis enhanced the resistance of powdery mildew, indicating that TuNAC69 may play an important role in disease resistance to other pathogens.

\section{Results}

\subsection{The Transcript Levels of TuNAC69 Were Up-Regulated after Pst Infection}

To identify genes involved in YrU1-mediated stripe resistance, we analyzed RNAseq data in T. urartu accession PI428309, which contains the functional YrU1 gene. The transcripts of TuNAC69 in PI428309 were increased significantly after inoculation with Pst CYR33 (Figure 1a). To verify the results of RNA-seq, we examined the TuNAC69 transcript levels by qRT-PCR at 0 days post-inoculation (dpi), 1 dpi and 4 dpi with Pst CYR33. As shown in Figure 1b, the transcripts of TuNAC69 accumulated at a much higher level at $1 \mathrm{dpi}$ and 4 dpi. We also analyzed the transcripts levels of TuNAC69 in the susceptible T. urartu accession G1812, which lacks the functional YrU1 gene. After inoculation, the transcripts of TuNAC69 in PI428309 were much higher than that in G1812 at 1 dpi and 4 dpi. On 4 dpi, the transcript level of TuNAC69 in G1812 was similar to the uninfected plants, while in PI428309, the transcript level was still much higher than that in the uninfected plants (Figure 1b). PI428309 also contains a functional powdery mildew resistance gene, Pm60, and confers resistance to Blumeria graminis f. sp. tritici (Bgt) [26]. In order to examine whether TuNAC69 is induced by powdery mildew pathogen, we infected PI428309 with Bgt E09 and examined the transcripts of TuNAC69 at different time points after Bgt E09 inoculation. In contrast, there was no significant change in the transcript levels of TuNAC69 after inoculated with Bgt E09 (Figure 1c). These results indicate that TuNAC69 may be involved in the resistance for YrU1-mediated stripe rust of wheat. 
(a)

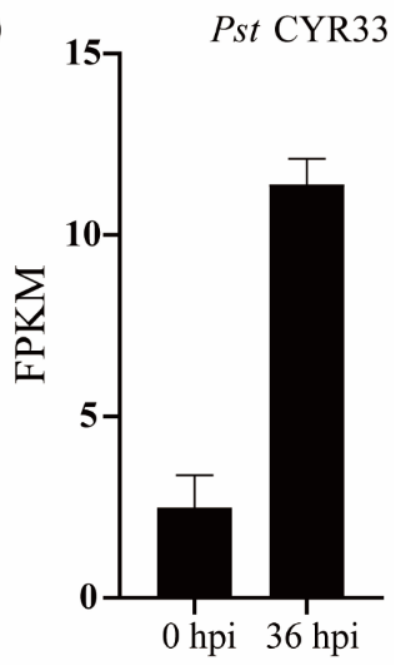

(b)

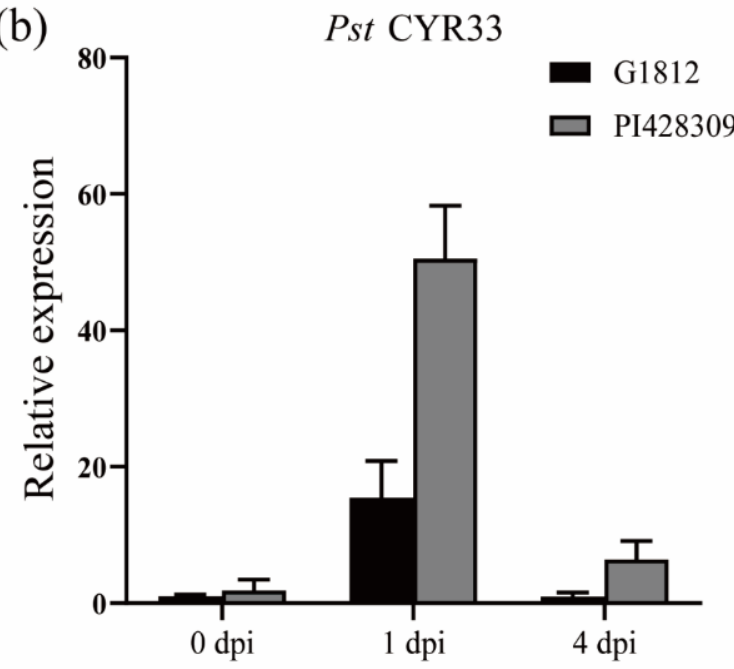

(c)

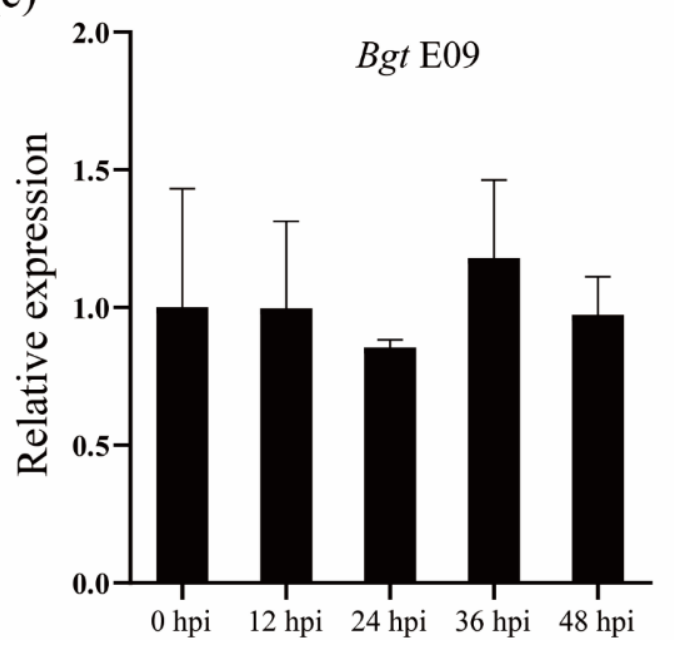

Figure 1. Expression analysis of TuNAC69 in PI428309 and G1812. (a) RNA-seq results showed that the expression level of TuNAC69 in PI428309 was significantly up-regulated after inoculation with Pst. (b) TuNAC69 was up-regulated in PI428309, and was still maintained at a high level at 4 dpi. (c) The expression of TuNAC69 was not significantly changed after inoculation with Bgt E09.

\subsection{TuNAC69 Is Well Conserved among Plant Species}

The full length of TuNAC69 coding sequence encodes a protein of 359 amino acids, with a relative molecular weight of about $40 \mathrm{kDa}$. TuNAC69 has the typical structure of NAC family members, with a conserved N-terminal NAM domain (Figure 2a). In the genome of Triticum aestivum, TaNAC69-1, TaNAC69-2 and TaNAC69-3 are highly similar to TuNAC69 (Figure S1), located on chromosomes 5B, 5D, and 5A, respectively. Compared with them, the TuNAC69 has an amino acid sequence identity of 96.1\% with TaNAC69-1, 95.8\% with TaNAC69-2, 100\% with TaNAC69-3 (Figure 2b). As shown in Figure 2c, the NAC69 homologous are well conserved and presented in different plant species. 
(a)

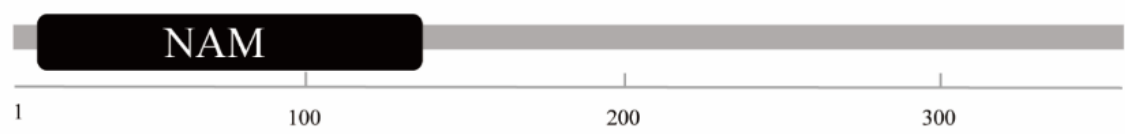

(b)

TaNAC69-1
TaNAC69-2
TaNAC69-3
TuNAC69
Consensus
TaNAC69-1
TaNAC69-2
TaNAC69-3
TuNAC69
Consensus
TaNAC69-1
TaNAC69-2
TaNAC69-3
TuNAC69
Consensus
TaNAC69-1
TaNAC69-2
TaNAC69-3
TuNAC69
Consensus
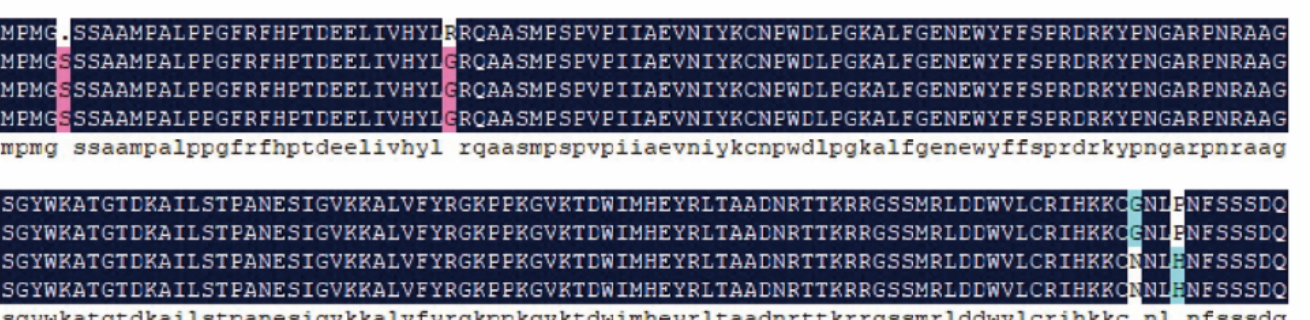

(c)

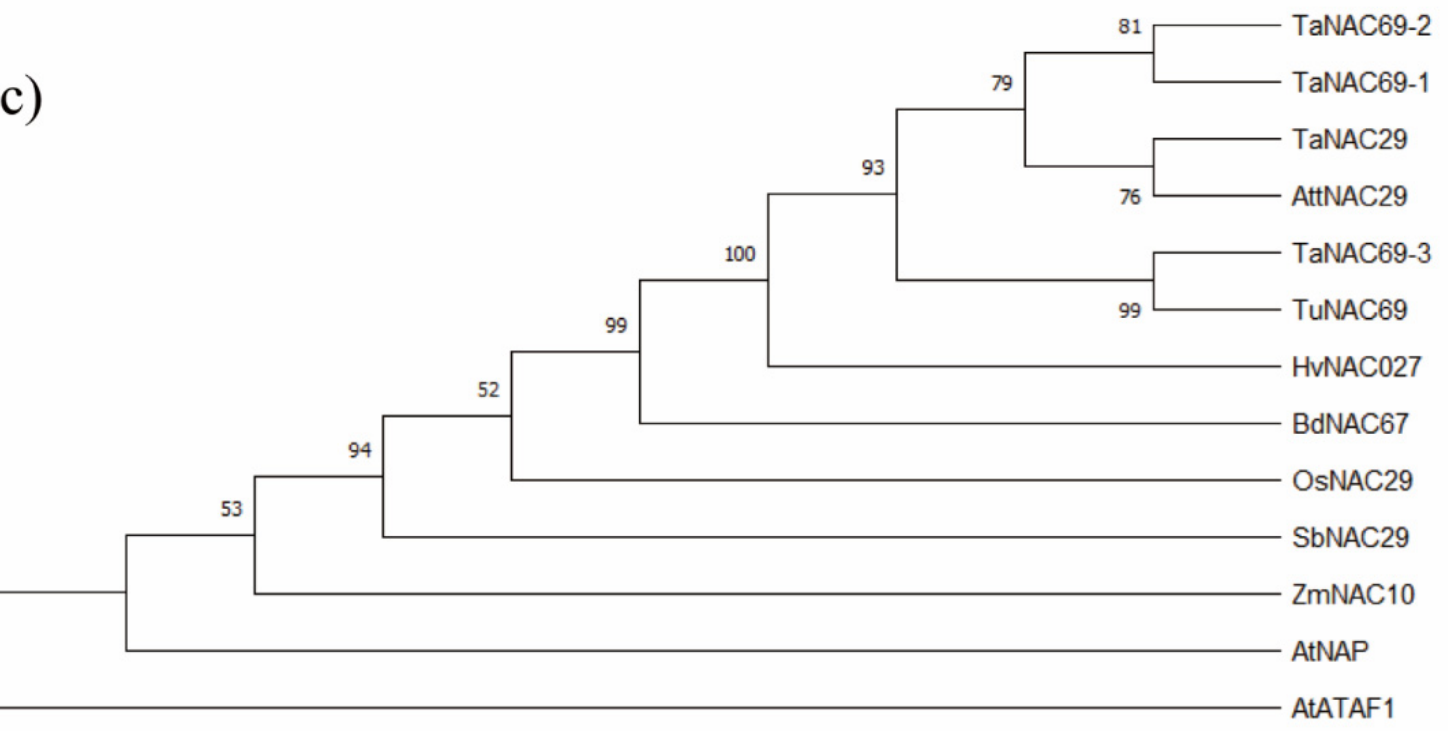

Figure 2. Analysis of TuNAC69. (a) Schematic representation of TuNAC69 protein domain. (b) Multiple comparisons between TuNAC69 and its homologs in wheat. (c) Phylogenetic analysis of TuNAC69. Different NAC transcription factors from Triticum aestivum (Ta), Hordeum vulgare subsp. Vulgare (Hv), Aegilops tauschii subsp. tauschii (Att), Sorghum bicolour (Sb), Zea mays (Zm), Brachypodium distachyon (Bd) and Arabidopsis thaliana (At) were used for the phylogenetic analyses. The unrooted phylogenetic tree was depicted using the MEGA X program and was constructed using the neighborjoining method. TaNAC69-1 (AAU08785.1), TaNAC69-2 (XP_037440448.1), TaNAC69-3 (AAY44098.1), HvNAC027 (CBZ39285.1), TaNAC29 (AKC34071.1), OsNAC29 (XP_015615093.1), AttNAC29 (XP_020166974.1), AtNAP (NP_564966.1), AtATAF1 (NP_171677.1), BdNAC67 (XP_003577115.1), SbNAC29 (XP_002448919.1), ZmNAC10 (PWZ45967.1). 


\subsection{TuNAC69 Is Localized in the Nucleus with Transcriptional Activation Activity}

In order to examine the localization of TuNAC69, we created a construct to express TuNAC69 and Green fluorescent protein (GFP) fusion protein, then transiently expressed it in wheat and tobacco Nicotiana benthamiana. TuNAC69 proteins mainly localized in the nucleus in both wheat and N. benthamiana cells (Figure 3a,b), which is consistent with the localization characteristics of transcription factors. Immunoblot analysis indicated that TuNAC69-GFP protein was correctly expressed in N. benthamiana (Figure 3c).

\section{(a) \\ Bright Field \\ Merged}

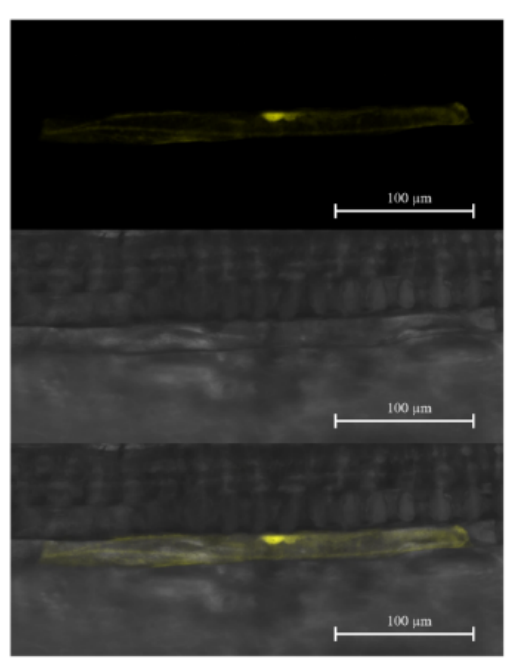

(b)

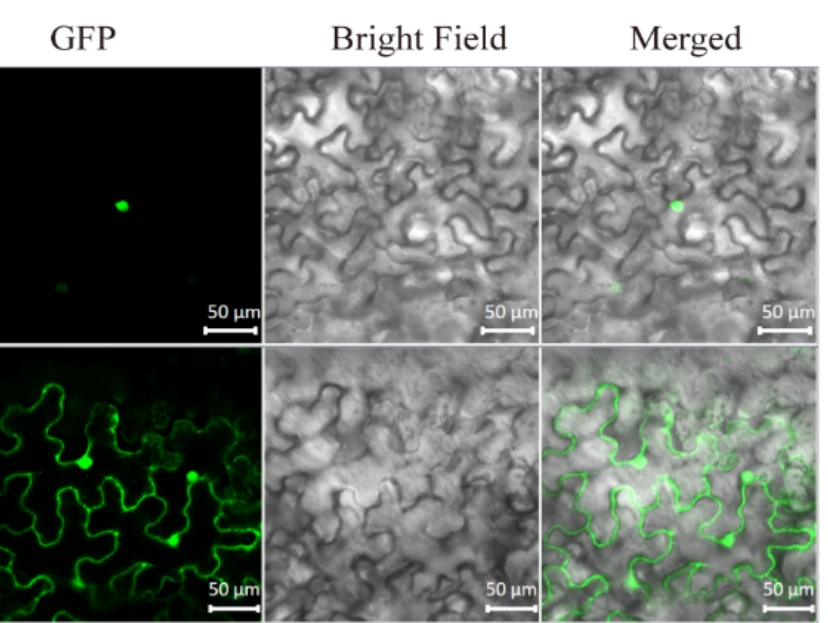

\section{pUBI:TuNAC69-YFP}
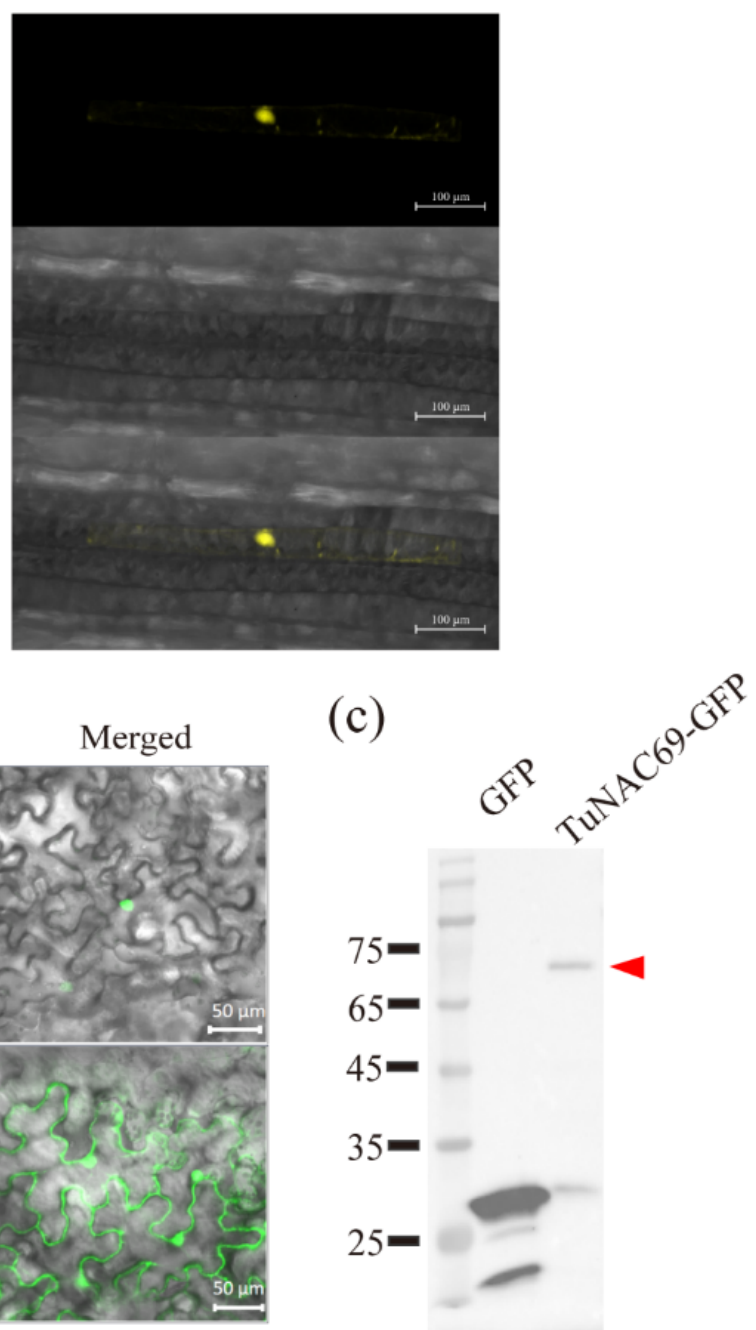

Figure 3. Subcellular localization of the TuNAC69-GFP fusion protein in wheat and tobacco. (a) TuNAC69 mainly localizes in the nucleus of T. aestivum cells. Bar $=100 \mu \mathrm{m}$. (b) TuNAC69 localized in the nucleus of N. benthamiana cells. Bar $=50$. (c) Accumulation of TuNAC69-GFP in $N$. benthamiana leaves by immunoblot analysis. The red triangle indicates TuNAC69-GFP.

TaNAC69-1 was shown to be able to inhibit TaIAA7 and TaSHY2 expression under drought stress [27-29], but the amino acid sequence comparison shows that the sequence of TuNAC69 is more similar with TaNAC69-3 in T. aestivum. In order to examine the transcriptional activation activity of TuNAC69, we constructed a full length of TuNAC69 and its different domains with the vector pGBKT7, and then transformed them into the yeast strain. The full length of TuNAC69, the N-terminal NAM domain, and the C-terminus were assessed respectively (Figure 4a). As shown in Figure 4b, TuNAC69 had strong transcriptional activation activity, and the $\mathrm{C}$-terminal of the protein provided the activity. 
(a) $\mathrm{pBD}$

pBD-TuNAC69-N

pBD-TuNAC69-C

pBD-TuNAC69

\section{GAL4-BD}

\section{GAL4-BD NAM domain}

178 AA

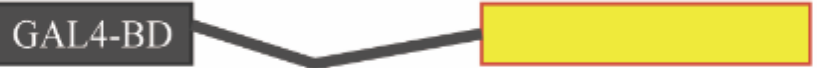

\section{GAL4-BD $\quad$ NAM domain}

\section{AA}
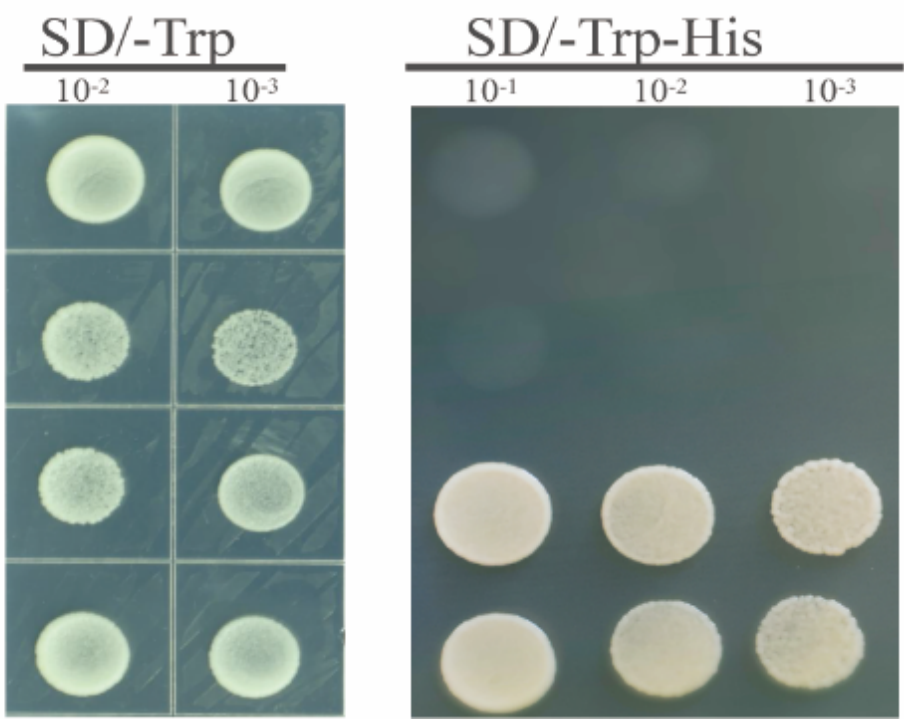

Figure 4. The C-terminal of TuNAC69 has transcriptional activation activity. (a) Schematic diagram indicated the GAL4-BD-fused TuNAC69 and truncated proteins of TuNAC69. From 1 to 178 amino acids of TuNAC69 were defined as N-terminal of TuNAC69. From 179 to 359 amino acids of TuNAC69 were defined as C-terminal of TuNAC69. (b) TuNAC69 and its C-terminal domain showed the activity of transcriptional activator in yeast.

\subsection{Knockdown TuNAC69 Leads to Enhanced Susceptibility to Pst in PI428309}

In order to determine whether TuNAC69 is involved in the YrU1-mediated stripe rust resistance, we used barley stripe mosaic virus (BSMV)-induced gene silencing (VIGS) system to knockdown TuNAC69 in PI428309, which contains a functional YrU1. Knockdown of TuNAC69 compromised the resistance to stripe rust Pst CYR33. In 14 days after inoculation, the number of uredia on the leaves with reduced TuNAC69 expression was denser than that of the control leaves, and no necrotic spot caused by cell death was observed, showing more susceptible symptoms (Figure 5). 
(a)
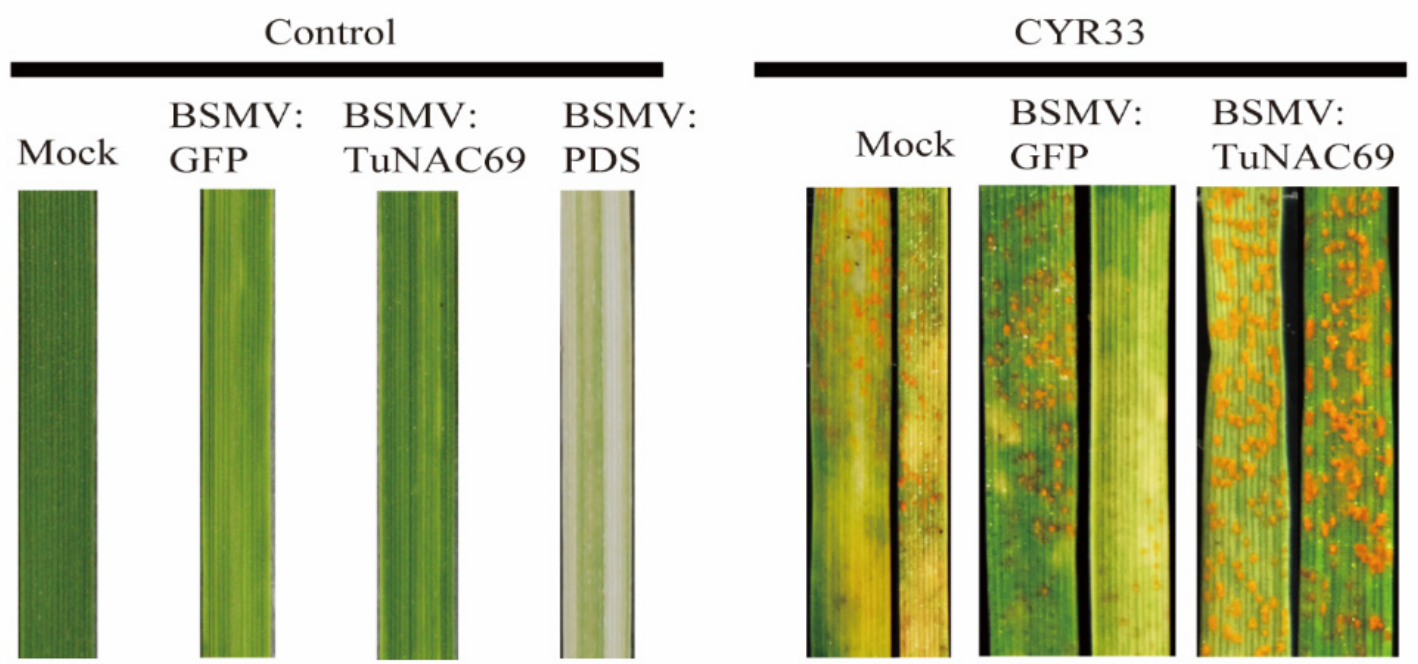

(b)

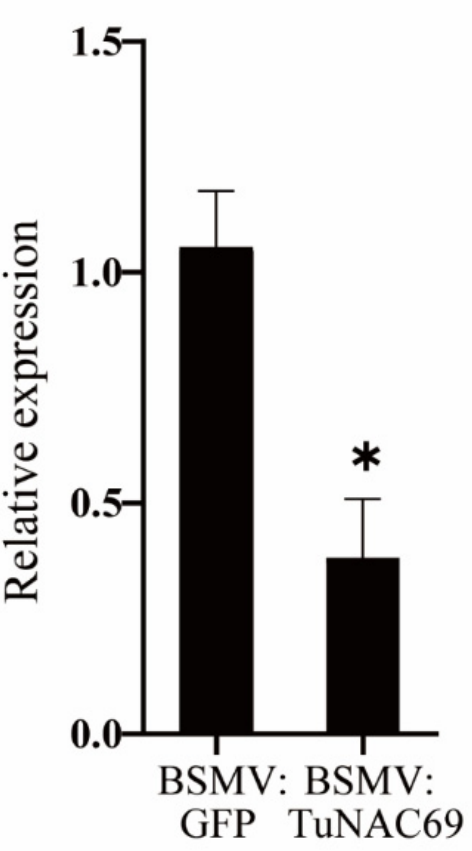

(c)

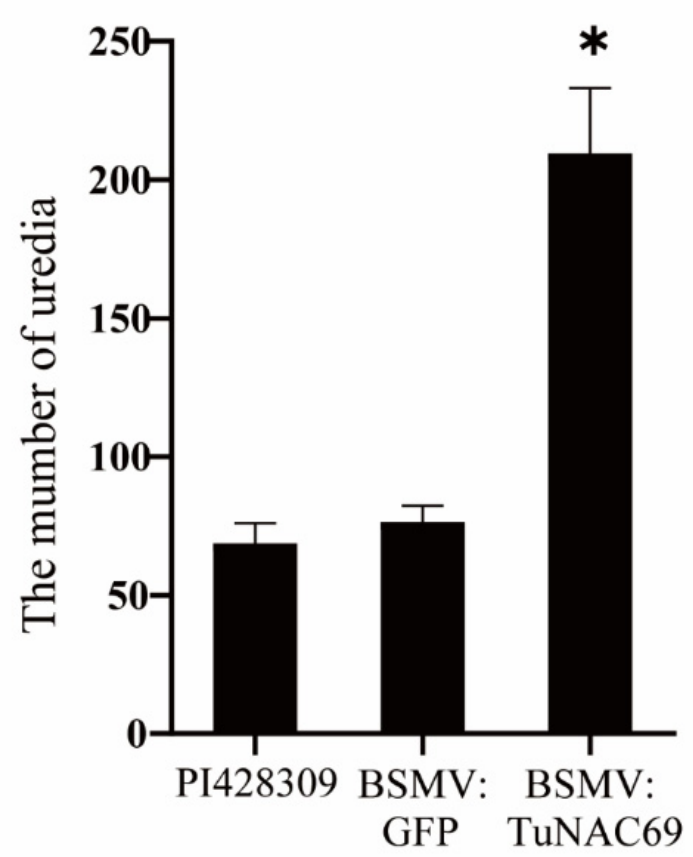

Figure 5. Barley stripe mosaic virus (BSMV)-induced silencing of TuNAC69 compromised the resistance of PI428309 to Pst CYR33. (a) PI428309 was inoculated with the BSMV on the second leaf. Inoculated with urediniospores of Pst CYR33 on the fourth leaf after 21 days. Leaves infected with Pst CYR33 were examined at $14 \mathrm{dpi}$. (b) The transcript levels of TuNAC69 were examined by quantitative reverse transcription PCR (qRT-PCR). TuACTIN was used as an internal control. (c) The number of uredia per $\mathrm{cm}^{2}$ on wheat leaves. Error bars represent $\pm \mathrm{SD}$ of values obtained from at least three independent biological samples. Statistically significant difference (Student's $t$-test): ${ }^{*}, p<0.05$.

In addition, to further characterize the stripe resistance, the infected leaves of wheat were taken at $48 \mathrm{hpi}, 72 \mathrm{hpi}$ and $120 \mathrm{hpi}$, and the mycelium of Pst was stained with wheat germ agglutinin (WGA), and the fungal growth was examined by confocal microscope. The number of hyphal branches (HB), haustorial mother cells (HMC) and haustoria (H) at 48 hpi were counted, respectively. The length of infection hyphae at 72 hpi infection and the infection unit area at 120 hpi were also measured [30]. As shown in Figure 6b, there was no significant difference, in the number of HB, HMC and H, between the TuNAC69 silenced plants and the control group. However, the length of infection hyphae and the 
infection unit area in TuNAC69 silenced plants were significantly larger than those in the control group (Figure $6 c, d$ ). Taken together, those results indicated that TuNAC69 plays a positive role in the resistance of PI428309 to stripe rust.

(a)

BSMV:GFP
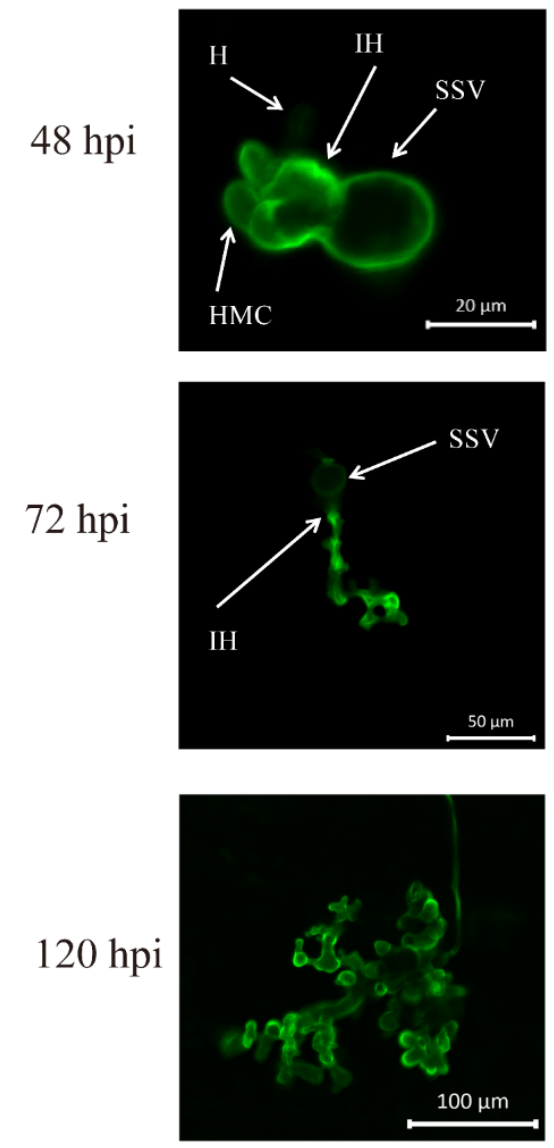

BSMV:TuNAC69
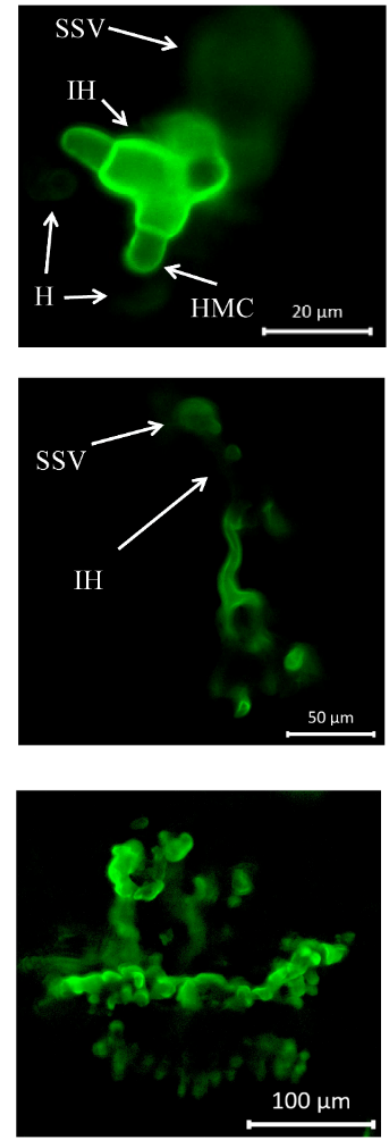

(b)

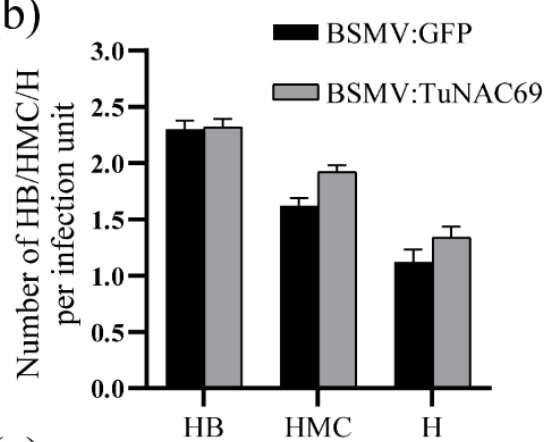

(c)

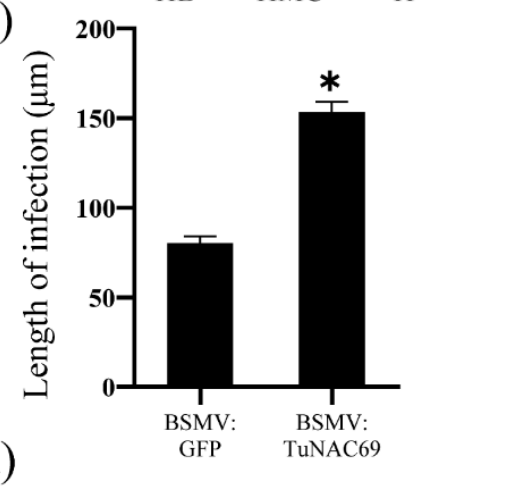

(d)

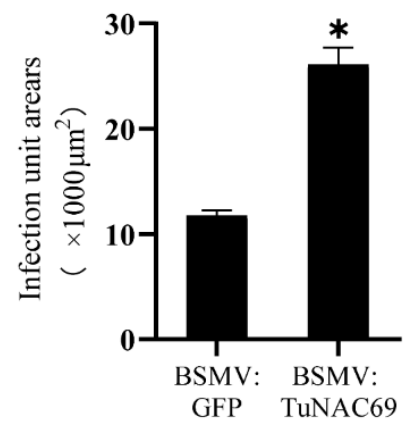

Figure 6. Histological observation of Pst. (a) The morphology of mycelium was observed by WGA staining at $48 \mathrm{hpi}, 72 \mathrm{hpi}$ and $120 \mathrm{hpi}$. The Bar is $20 \mu \mathrm{m}, 50 \mu \mathrm{m}$ or $100 \mu \mathrm{m}$, as indicated. (b) The numbers of $\mathrm{HB}, \mathrm{HMC}$ and $\mathrm{H}$ of $P s t$ in each infected site were counted and the average was calculated, and there was no significant difference at 48 hpi. (c) The length of IH in each infected site was measured at $72 \mathrm{hpi}$. (d) The area of each infected site of $120 \mathrm{hpi}$ inoculated with stripe rust. The mycelium length and extended infection area in BSMV:TuNAC69 plants were measured. Values represent the mean $\pm \mathrm{SE}$ of three independent samples $(n=50)$. Statistically significant difference (Student's $t$-test): $*, p<0.05$.

Besides of the stripe resistance of the YrU1 gene, PI423809 also contains a powdery mildew resistance gene Pm60, which is highly resistant to Bgt E09 [26]. In order to test whether TuNAC69 is specifically involved in YrU1-mediated stripe rust resistance, we inoculated the TuNAC69 silenced PI423809 plants and the control group of PI428309 with Bgt E09. Silencing of TuNAC69 did not affect powdery mildew resistance (Figure S2), indicating that TuNAC69 is not involved in Pm60-mediated resistance to Bgt E09 in PI428309. 


\subsection{Transient Overexpression of TuNAC69 Enhanced the Resistance to Powdery Mildew in Wheat}

To study whether TuNAC69 is involved in basal defense and disease resistance to other pathogens, we first performed transient expression mediated by particle bombardment, and then assessed the effects on the powdery mildew resistance. In this assay, we transiently expressed TuNAC69 in the susceptible T. aestivum accession Fielder. As shown in Figure 7, transient expression of TuNAC69 in the leaves of Fielder significantly decreased the haustorium index when compared to transient expression of PGY, and the empty vector used as a control, indicating that TuNAC69 plays positive roles in resistance against Bgt E09.

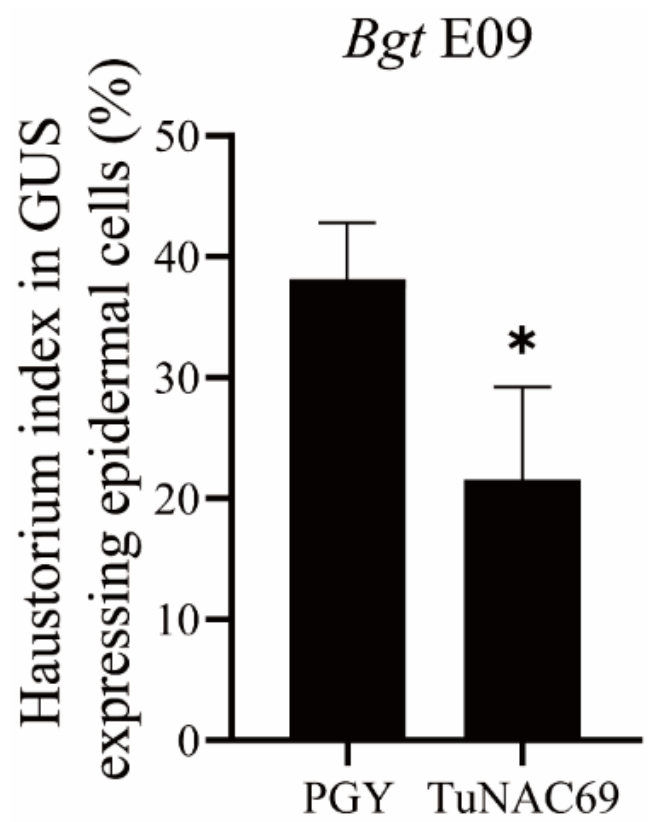

Figure 7. Transient overexpression of TuNAC69 enhanced the resistance to powdery mildew in wheat. Single-cell transient expression of TuNAC69 on the detached leaves of the susceptible wheat accession Fielder. Compared with control PGY, overexpression of TuNAC69 significantly reduced haustorium index after inoculation with Bgt E09. Statistically significant difference (Student's $t$-test): ${ }^{*}, p<0.05$.

\subsection{Overexpression of TuNAC69 Enhanced the Resistance to Powdery Mildew in Arabidopsis}

To further study the role of TuNAC69 in disease resistance, we overexpressed TuNAC69 in the model plant Arabidopsis thaliana, and infected plants with powdery mildew fungus. The TuNAC69 fused with a HA tag was driven by 35 S promoter, and was transformed to Arabidopsis thaliana accession Col-0. As shown in Figure 8a, the TuNAC69-HA protein was properly accumulated. Two independent transgenic plants overexpressing TuNAC69 (35S:TuNAC69-HA-1, 2) were inoculated with powdery mildew fungus G. cichoracearum, and the number of conidiophores was counted at $5 \mathrm{dpi}$. As shown in Figure 8b, the conidiophores per colony in overexpressed plants were significantly lower than that of control plants (Figure 8b). In $7 \mathrm{dpi}$, the leaves of the two representative overexpressed lines supported much less growth of powdery mildew fungi, and displayed some necrotic cell death (Figure 8c,d). These results indicate that overexpression of TuNAC69 in Arabidopsis thaliana can increase the resistance to G. cichoracearum and lead to cell death in plants. 
(a)

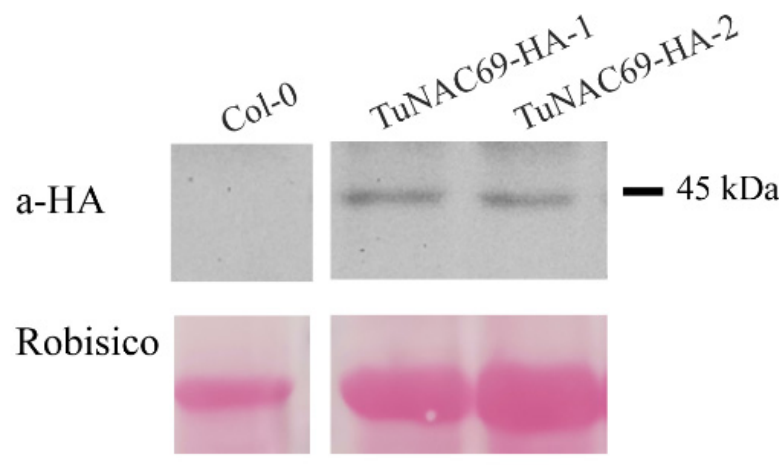

(b)

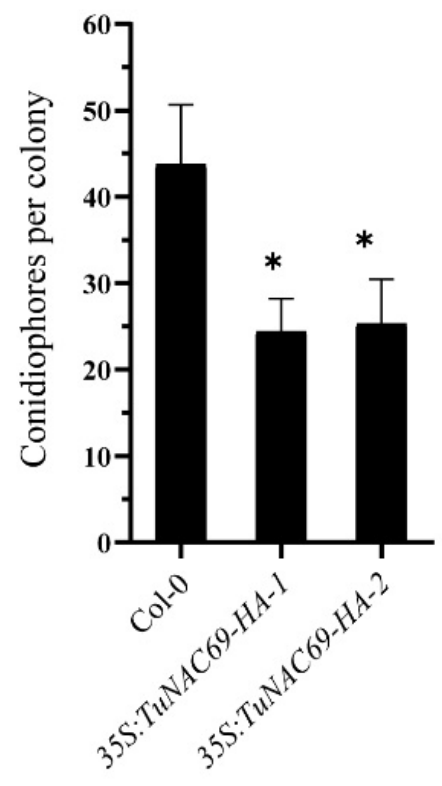

(c)

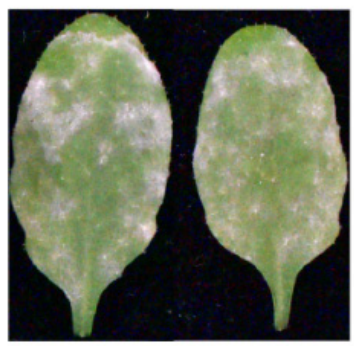

(d)
Col-0

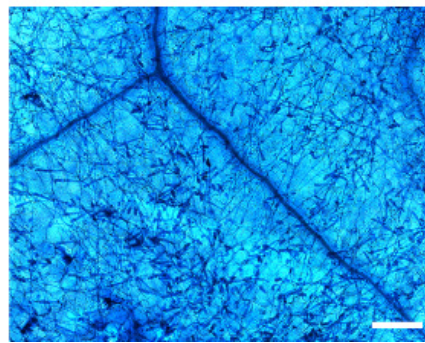

35S:TuNAC69-HA-1

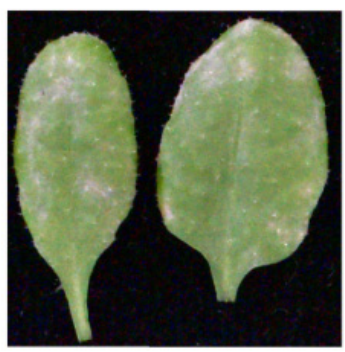

35S:TuNAC69-HA-1

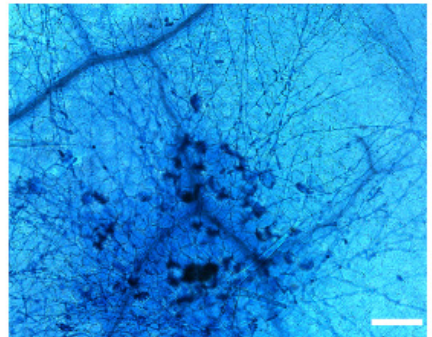

35S:TuNAC69-HA-2

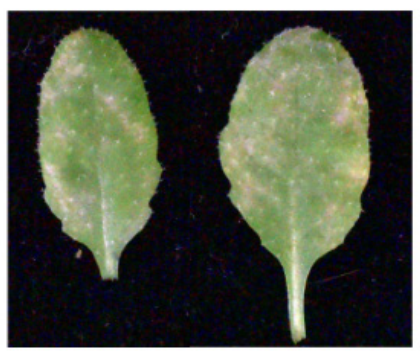

35S:TuNAC69-HA-2

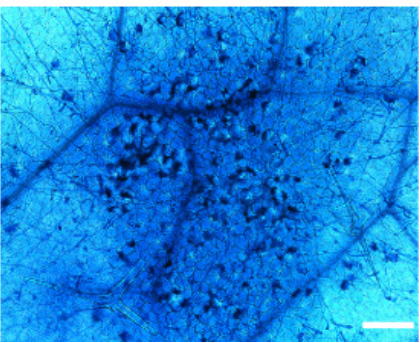

Figure 8. The TuNAC69-overexpressing Arabidopsis exhibits increased resistance to G. cichoracearum. (a) Accumulation of TuNAC69 protein was examined by immunoblot analysis in the transgenic Arabidopsis. (b) Quantitative analysis of conidiophore formation in Col-0, 35S:TuNAC69-HA-1 and 35S:TuNAC69-HA-2 plants at 5 dpi. Error bars represent \pm SD from three independent experiments $(n>30)$. Statistically significant difference (Student's $t$-test): ${ }^{*}, p<0.05$. (c) Four-week-old plants were infected with G. cichoracearum and the representative leaves were photographed at $7 \mathrm{dpi}$. (d) Trypan blue staining of leaves after infection with G. cichoracearum at $7 \mathrm{dpi}(\mathrm{Bar}=200 \mu \mathrm{m})$.

\section{Discussion}

YrU1 is a unique NLR protein containing an ANK domain and a WRKY domain, which only exists in wheat relatives. Understanding the molecular mechanism of YrU1 is important for wheat disease resistance breeding and the interpretation of the mechanism of NLR proteins. In this study, through analyzing the RNA-seq data, we found that a NAC 
transcription factor TuNAC69 was up-regulated in Pst CYR33 infected leaves in T. urartu PI428309, which contains the functional stripe rust resistance YrU1 gene and powdery mildew resistance Pm60 gene. The silencing of TuNAC69 in PI428309 reduced the resistance to Pst CYR33, but had no effect on powdery mildew resistance to Bgt E09. Those results indicated that TuNAC69 may be involved in YrU1-mediated immune response, but not Pm60-mediated resistance.

Previous works have shown that NAC transcription factors play important roles in biotic and abiotic stresses [31,32]. In wheat, the expression of TaNAC69, the close homolog of TuNAC69, was up-regulated by drought and cold [28]. Overexpression of TaNAC69 led to enhanced expression levels of some stress up-regulated genes. And TaNAC69 and its rice homolog are able to bind to the promoter elements of three rice genes, including chitinase, ZIM, and glyoxalase I and an Arabidopsis glyoxalase I family gene, which are homologs of the up-regulated stress genes in the overexpression of TaNAC69 [29]. TaNAC691 overexpression in the roots (with root-predominant promoters) led to lower expression of TaSHY2 and TaIAA7, the homologs of negative root growth regulators in Arabidopsis. Further experiments showed that TaNAC69-1 binds to TaSHY2 and TaIAA7 promoters as a transcriptional repressor, and is likely to function in promoting root elongation in drying soil [27]. Emerging evidence show that TaNAC69 is also involved in plant disease resistance. Analyses of the Affymetrix expression data showed that the expression of TaNAC69 gene was up-regulated in rust-infected wheat plants [29]. RNA-seq data and quantitative real-time PCR analysis showed that the expression of TaNAC069, which is highly homologous to TaNAC69, was induced by leaf rust pathogen, and the resistance to leaf rust was significantly reduced in TaNAC069-silenced plants [33]. Some upstream transcription factors and interacting targets of TaNAC069 were identified. However, how TaNAC069 contributes to leaf rust, and whether those interacting targets function in plant disease resistance are remained to be determined.

In the previous study, we reported that the ANK and WRKY domain containing NLR protein $\mathrm{YrU1}$ plays important roles in wheat stripe rust resistance. Although how YrU1 functions is not clear, it has been hypothesized that the WRKY domain may bind the pathogen effector resulting in the activated of disease resistance. And the ANK domain may recruit additional components to activate downstream signaling [8]. In this study, we showed that the transcription factor TuNAC69 is required by YrU1-mediated stripe resistance. NLRs usually activate plant immunity by the perception of pathogen effectors. Whether TuNAC69 is activated after perception of pathogen effectors by YrU1 and how TuNAC69 modulates YrU1-mediated resistance are remained to be determined. Previously, it has been shown that some plant transcription factors directly interact with NLRs, and play critical roles in NLR-mediated resistance. For instance, in barley, intracellular mildew A (MLA 10) NLR protein functions in the nucleus to confer resistance against the powdery mildew fungus. Recognition of the fungal avirulence A10 effector by MLA10 induces nuclear associations between MLA10 and WRKY transcription factors HvWRKY1/2. And HvWRKY1/2 proteins act as repressors of basal defense [34]. Further study showed that barley NLR MLA10 directly interacts with two antagonistically acting transcription factors, MYB6 and WRKY1 [35]. The transcription factor MYB6 associates with MLA10 and functions as an immediate and positive signaling component for the transcriptional reprogramming to initiate disease resistance [34]. In addition, rice transcription factor OsWRKY19 interacts with NLR protein OsRLR1 and contributes to resistance to the fungal pathogen Magnaporthe oryzae and the bacterial pathogen Xanthomonas oryzae pv. oryzae mediated by OsRLR1 [36]. The transcription factor TuNAC69 is localized in the nucleus with transcriptional activation activity. It would be interesting to examine whether TuNAC69 interact with YrU1, and whether the interaction contributes to stripe rust resistance.

Interestingly, although transiently silenced TuNAC69 in T. urartu PI428309 had no effect on Pm60-mediated powdery mildew resistance, overexpression of TuNAC69 enhanced the resistance to powdery mildew in susceptible common wheat and Arabidopsis. In those cases, there are no functional NLRs present, suggesting that TuNAC69 may also function in basal 
defense. Based on the above results, we speculated that TuNAC69 is not only involved in YrU1-mediated immune response but also plays an important role in resistance to other pathogens. TuNAC69 is well conserved and present among plant species, and it would be very interesting to investigate whether NAC69 in other plant species also plays important roles in plant disease resistance.

Taken together, we show that TuNAC69 is localized in the nucleus with transcriptional activation activity and is involved in $\mathrm{YrU1}$-mediated immune response. Our findings provide new insight into the role of $\mathrm{YrU1}$ and TuNAC69 in wheat rust resistance and broaden the understanding of the role of NAC transcription factors in plant disease resistance. The important questions to be addressed include how plants transduces the immune signal to TuNAC69 to modulate transcriptional reprogramming in defense responses, and what are the direct target genes of TuNAC69, which contribute to YrU1-mediated resistance and basal immunity.

\section{Materials and Methods}

\subsection{Plant Materials and Pathogens Growth Conditions}

Plants used in this study were grown in a greenhouse at $22{ }^{\circ} \mathrm{C}$ with approximately $60 \%$ relative humidity under a $9 \mathrm{~h}$-light $/ 15 \mathrm{~h}$-dark photoperiod, unless indicated otherwise. T. urartu accession PI428309 inoculated with Pst was cultured in the greenhouse at $16{ }^{\circ} \mathrm{C}$ and 16-h-light/8-h-dark photoperiod. The hexaploid wheat inoculated with Bgt E09 was cultured in an incubator at $22{ }^{\circ} \mathrm{C}$ under a $12 \mathrm{~h}: 12 \mathrm{~h}$, light:dark photoperiod. The hexaploid wheat cultivar Mingxian169 was used to maintain the Pst CYR33 used in the experiments. And hexaploid wheat cultivar Fielder was used to maintain the Bgt E09. Powdery mildew (Golovinomyces cichoracearum UCSC1) was cultivated with Arabidopsis pad4-1 [37].

\subsection{Quantitative Real-Time RT-PCR}

Extraction of total RNA using TRIzol reagent, synthesis of first-strand cDNA and RT-qPCR were performed as described previously [38]. The TuACTIN gene was used as an internal control.

\subsection{Phylogenetic Analyses}

A full length of TuNAC69 (TRIUR3_14542) was identified based on the sequence of the corresponding gene in T. urartu G1812. The corresponding primers were designed respectively, and the TuNAC69 gene fragment was obtained by PCR using PI428309 cDNA as a template. The primers used in this research are listed in Table S1. The sequences of NAC transcription factors were retrieved using the NCBI database (https://www.ncbi. nlm.nih.gov / (accessed on 13 September 2021)) and Gramene database (https: / / ensembl. gramene.org/index.html (accessed on 21 June 2021)). The protein domains were predicted by the NCBI SMART program (http: / / smart.embl-heidelberg.de/ (accessed on 23 August 2021)) and UniProt database (https:/ / www.uniprot.org/ (accessed on 7 October 2021)). The sequences were aligned to generate a phylogenetic tree by using MEGA X.

\subsection{Virus Induced TuNAC69 Gene Silencing}

Barley stripe mosaic virus (BSMV) induced gene silencing system (VIGS) was used for functional gene verification. The $197 \mathrm{bp}$ fragment of TuNAC69 with high specificity was fused to the $\gamma$ vector. The RNA $\alpha, \beta, \gamma$-TuNAC69, $\gamma$-PDS and $\gamma$-GFP were generated by vitro transcription using T7 RNA polymerase. The $\alpha, \beta$ and $\gamma$-TuNAC69 ( $\gamma$-PDS or $\gamma$-GFP) RNA of BSMV were mixed at equal proportion and mixed with an equal volume of GKP buffer. Then, $10 \mu \mathrm{L}$ of the mixture was dropped and gently rubbed into the wheat leaves with a PE glove, then protected from light and moisturized for $24 \mathrm{~h}$ to inoculate the second fully expanded leaves of the wheat seedlings. The fifth leaves were used to evaluate the resistance to Pst and determine the expression levels of TuNAC69 by qRT-PCR. 


\subsection{Histological Analysis of Fungal Growth}

The leaves of different periods were decolorized with $1 \mathrm{M} \mathrm{KOH}$ with $0.05 \%(v / v)$ Silwet L-77 at $37^{\circ} \mathrm{C}$ for $12 \mathrm{~h}$, rinsed with $50 \mathrm{mM}$ Tris (pH 7.5) for $20 \mathrm{~min}$, then stained with $20 \mu \mathrm{g} / \mathrm{mL}$ WGA-FITC at room temperature for $15 \mathrm{~min}$, and then observed with confocal microscope as described [39].

\subsection{Single-Cell Transient Gene Expression Assay}

The single-cell transient expression assay was performed as described previously [34]. The reporter plasmid containing $\beta$-glucuronidase (GUS) gene was mixed with plasmid pUBI:PGY or pUBI:TuNAC69 (molar ratio 1:1; total DNA less than $2.5 \mu \mathrm{g}$ ) to express transiently in epidermal cells of wheat leaves by biolistic delivery. Leaves were incubated in GUS staining solution for about $12 \mathrm{~h}$ at $37^{\circ} \mathrm{C}$ at $2 \mathrm{dpi}$. And then the samples were decolored and observed. The haustorium index was determined as the percentage of number of spores that developed haustorium in effective spores and the experiment was repeated three times independently, each observing at least 40 interactions.

\subsection{Subcellular Localization Assay in Nicotiana Benthamiana}

Agrobacterium tumefaciens GV3101 containing the recombinant plasmid $p$ CAMBIA1300TuNAC69-GFP was culture for $12 \mathrm{~h}$, and collected by centrifugation at $4000 \mathrm{rpm}$ and resuspended to $\mathrm{OD}_{600}=1.5$ with injection buffer $(10 \mathrm{mM}$ MES, $10 \mathrm{mM} \mathrm{MgCl} 2,120 \mu \mathrm{M}$ Acetosyringone) and injected into Nicotiana benthamiana. Then the plants were moved to a greenhouse under a 9-h-light/15-h-dark photoperiod. GFP signals of TuNAC69-GFP were visualized by confocal microscope $48 \mathrm{~h}$ after infiltration.

\subsection{Protein Extraction and Immunoblot Analysis}

Plants were ground in liquid nitrogen using a mortar and pestle, total protein was extracted using the protein extraction solution (50 mM Tris-MES [pH 8.0], $0.5 \mathrm{M}$ Sucrose, 1 $\mathrm{mM} \mathrm{MgCl}, 10 \mathrm{mM}$ EDTA, $5 \mathrm{mM}$ DTT, and 1\% [w/v] protease inhibitor cocktail S8830) [40]. The samples were placed on ice for $30 \mathrm{~min}$, turning it upside down twice, and then samples were centrifuged for $15 \mathrm{~min}$ at $12,000 \times \mathrm{g}$ and the upper layer liquid were collected. Immunoblot analysis was performed as described previously [41].

\subsection{Transcriptional Activation Activity of TuNAC69}

Full length of TuNAC69, the N-terminal of TuNAC69 (1-531 bp) and the C-terminal of TuNAC69 (531-1077 bp) were cloned into pGBKT7, respectively. And the derived recombinant plasmids were separately transformed into Saccharomyces cerevisiae strain AH109. Transformed cells were cultured in SD/-Trp and SD/-Trp/-His, respectively, at $30{ }^{\circ} \mathrm{C}$ as described $[42,43]$.

\subsection{Genetic Transformation of Arabidopsis thaliana}

The TuNAC69 construct was introduced into the Agrobacterium tumefaciens strain GV3101. Agrobacterium with fused TuNAC69 recombinant plasmid was suspended in a $5 \%(w / v)$ sucrose solution buffer containing $0.02 \%(v / v)$ Silwet L-77 and transformed into Arabidopsis thaliana accession Columbia-0 (Col-0) using the floral dip method [44]. The Arabidopsis were grown at a greenhouse at $22{ }^{\circ} \mathrm{C}$ under a 16-h-light/8-h-dark photoperiod for seed setting [45]. Transformants were selected on $\frac{1}{2}$ Murashige and Skoog medium $\left(\frac{1}{2} \mathrm{MS}\right)$ containing $0.005 \%(w / v)$ kanamycin. The stably transformed plants were identified in the T3 generation and used for further analysis.

\section{Conclusions}

In this study, we found that a NAC transcription factor TuNAC69 was up-regulated after being inoculated with Pst CYR33 in the presence of YrU1. TuNAC69 was mainly localized in the nucleus and showed transcriptional activation in yeast. Transiently silenced of TuNAC69 in diploid wheat Triticum urartu PI42839 that contains YrU1 by VIGS reduced 
the resistance to stripe rust. In addition, overexpression of TuNAC69 in common wheat and Arabidopsis enhanced the resistance to powdery mildew. In summary, our study indicates that TuNAC69 positively regulates YrU1-mediated stripe rust resistance and likely plays an important role in disease resistance to other pathogens.

Supplementary Materials: The following supporting information can be downloaded at: https: //www.mdpi.com/article/10.3390/ijms23010564/s1.

Author Contributions: D.T. and H.W. conceived and designed the research. Y.X., H.Z. and S.Z. carried out most experiments. Y.X., S.Z., B.W. and D.T. analyzed the data. Y.X., W.W., H.W. and D.T. wrote the manuscript. All authors have read and agreed to the published version of the manuscript.

Funding: The work was supported by grants from the National Natural Science Fundation of China (31830077 and 32001444).

Institutional Review Board Statement: Not applicable.

Informed Consent Statement: Not applicable.

Data Availability Statement: Sequence data can be found in GenBank databases under the following numbers: TaNAC69-1 (AAU08785.1), TaNAC69-2 (XP_037440448.1), TaNAC69-3 (AAY44098.1), HvNAC027 (CBZ39285.1), TaNAC29 (AKC34071.1), OsNAC29 (XP_015615093.1), AttNAC29 (XP_020166974.1), AtNAP (NP_564966.1), AtATAF1 (NP_171677.1), BdNAC67 (XP_003577115.1), SbNAC29 (XP_002448919.1), ZmNAC10 (PWZ45967.1).

Acknowledgments: We thank Xiangqi Zhang for BSMV constructs and Bgt isolate E09.

Conflicts of Interest: The authors declare no conflict of interest.

\section{References}

1. Beddow, J.M.; Pardey, P.G.; Chai, Y.; Hurley, T.M.; Kriticos, D.J.; Braun, H.J.; Park, R.F.; Cuddy, W.S.; Yonow, T. Research investment implications of shifts in the global geography of wheat stripe rust. Nat. Plants 2015, 1, 15132. [CrossRef] [PubMed]

2. Chai, Y.; Pardey, P.G.; Hurley, T.M.; Senay, S.D.; Beddow, J.M. A Probabilistic Bio-Economic Assessment of the Global Consequences of Wheat Leaf Rust. Phytopathology 2020, 110, 1886-1896. [CrossRef] [PubMed]

3. Klymiuk, V.; Yaniv, E.; Huang, L.; Raats, D.; Fatiukha, A.; Chen, S.; Feng, L.; Frenkel, Z.; Krugman, T.; Lidzbarsky, G.; et al. Cloning of the wheat Yr15 resistance gene sheds light on the plant tandem kinase-pseudokinase family. Nat. Commun. 2018, 9, 3735. [CrossRef] [PubMed]

4. $\quad$ Krattinger, S.G.; Lagudah, E.S.; Spielmeyer, W.; Singh, R.P.; Huerta-Espino, J.; McFadden, H.; Bossolini, E.; Selter, L.L.; Keller, B. A putative ABC transporter confers durable resistance to multiple fungal pathogens in wheat. Science 2009, 323, 1360-1363. [CrossRef] [PubMed]

5. Fu, D.; Uauy, C.; Distelfeld, A.; Blechl, A.; Epstein, L.; Chen, X.; Sela, H.; Fahima, T.; Dubcovsky, J. A kinase-START gene confers temperature-dependent resistance to wheat stripe rust. Science 2009, 323, 1357-1360. [CrossRef]

6. Moore, J.W.; Herrera-Foessel, S.; Lan, C.; Schnippenkoetter, W.; Ayliffe, M.; Huerta-Espino, J.; Lillemo, M.; Viccars, L.; Milne, R.; Periyannan, S.; et al. A recently evolved hexose transporter variant confers resistance to multiple pathogens in wheat. Nat. Genet. 2015, 47, 1494-1498. [CrossRef]

7. Zhang, C.; Huang, L.; Zhang, H.; Hao, Q.; Lyu, B.; Wang, M.; Epstein, L.; Liu, M.; Kou, C.; Qi, J.; et al. An ancestral NB-LRR with duplicated 3'UTRs confers stripe rust resistance in wheat and barley. Nat. Commun. 2019, 10, 4023. [CrossRef]

8. Wang, H.; Zou, S.; Li, Y.; Lin, F.; Tang, D. An ankyrin-repeat and WRKY-domain-containing immune receptor confers stripe rust resistance in wheat. Nat. Commun. 2020, 11, 1353. [CrossRef]

9. Marchal, C.; Zhang, J.; Zhang, P.; Fenwick, P.; Steuernagel, B.; Adamski, N.M.; Boyd, L.; McIntosh, R.; Wulff, B.B.H.; Berry, S.; et al. BED-domain-containing immune receptors confer diverse resistance spectra to yellow rust. Nat. Plants 2018, 4, 662-668. [CrossRef]

10. Cui, H.; Tsuda, K.; Parker, J.E. Effector-triggered immunity: From pathogen perception to robust defense. Annu. Rev. Plant Biol. 2015, 66, 487-511. [CrossRef]

11. Wang, W.; Feng, B.; Zhou, J.M.; Tang, D. Plant immune signaling: Advancing on two frontiers. J. Integr. Plant Biol. 2020, 62, 2-24. [CrossRef]

12. Jones, J.D.; Vance, R.E.; Dangl, J.L. Intracellular innate immune surveillance devices in plants and animals. Science 2016, 354, aaf6395. [CrossRef] [PubMed]

13. Li, W.; Zhu, Z.; Chern, M.; Yin, J.; Yang, C.; Ran, L.; Cheng, M.; He, M.; Wang, K.; Wang, J.; et al. A Natural Allele of a Transcription Factor in Rice Confers Broad-Spectrum Blast Resistance. Cell 2017, 170, 114-126.e15. [CrossRef] [PubMed]

14. Zhai, K.; Deng, Y.; Liang, D.; Tang, J.; Liu, J.; Yan, B.; Yin, X.; Lin, H.; Chen, F.; Yang, D.; et al. RRM Transcription Factors Interact with NLRs and Regulate Broad-Spectrum Blast Resistance in Rice. Mol. Cell 2019, 74, 996-1009.e7. [CrossRef] [PubMed] 
15. Olsen, A.N.; Ernst, H.A.; Leggio, L.L.; Skriver, K. NAC transcription factors: Structurally distinct, functionally diverse. Trends Plant Sci. 2005, 10, 79-87. [CrossRef] [PubMed]

16. Souer, E.; van Houwelingen, A.; Kloos, D.; Mol, J.; Kors, R. The No Apical Meristem Gene of Petunia Is Required for Pattern Formation in Embryos and Flowers and Is Expressed at Meristem and Primordia Boundaries. Cell 1996, 85, 159-170. [CrossRef]

17. Aida, M.; Ishida, T.; Fukaki, H.; Fujisawa, H.; Tasaka, M. Genes involved in organ separation in Arabidopsis: An analysis of the cup-shaped cotyledon mutant. Plant Cell 1997, 9, 841-857. [CrossRef]

18. Wang, X.; Basnayake, B.M.; Zhang, H.; Li, G.; Li, W.; Virk, N.; Mengiste, T.; Song, F. The Arabidopsis ATAF1, a NAC transcription factor, is a negative regulator of defense responses against necrotrophic fungal and bacterial pathogens. Mol. Plant Microbe Interact. 2009, 22, 1227-1238. [CrossRef]

19. Zhu, X.; Chen, J.; Xie, Z.; Gao, J.; Ren, G.; Gao, S.; Zhou, X.; Kuai, B. Jasmonic acid promotes degreening via MYC2/3/4- and ANAC019/055/072-mediated regulation of major chlorophyll catabolic genes. Plant J. 2015, 84, 597-610. [CrossRef]

20. Sukiran, N.L.; Ma, J.C.; Ma, H.; Su, Z. ANAC019 is required for recovery of reproductive development under drought stress in Arabidopsis. Plant Mol. Biol. 2019, 99, 161-174. [CrossRef]

21. Jensen, M.K.; Rung, J.H.; Gregersen, P.L.; Gjetting, T.; Fuglsang, A.T.; Hansen, M.; Joehnk, N.; Lyngkjaer, M.F.; Collinge, D.B. The HvNAC6 transcription factor: A positive regulator of penetration resistance in barley and Arabidopsis. Plant Mol. Biol. 2007, 65, 137-150. [CrossRef]

22. Perochon, A.; Kahla, A.; Vranic, M.; Jia, J.; Malla, K.B.; Craze, M.; Wallington, E.; Doohan, F.M. A wheat NAC interacts with an orphan protein and enhances resistance to Fusarium head blight disease. Plant Biotechnol. J. 2019, 17, 1892-1904. [CrossRef]

23. Wang, B.; Wei, J.; Song, N.; Wang, N.; Zhao, J.; Kang, Z. A novel wheat NAC transcription factor, TaNAC30, negatively regulates resistance of wheat to stripe rust. J. Integr. Plant Biol. 2018, 60, 432-443. [CrossRef]

24. Feng, H.; Duan, X.; Zhang, Q.; Li, X.; Wang, B.; Huang, L.; Wang, X.; Kang, Z. The target gene of tae-miR164, a novel NAC transcription factor from the NAM subfamily, negatively regulates resistance of wheat to stripe rust. Mol. Plant Pathol. 2014, 15, 284-296. [CrossRef]

25. Zhang, N.; Yuan, S.; Zhao, C.; Park, R.F.; Wen, X.; Yang, W.; Zhang, N.; Liu, D. TaNAC35 acts as a negative regulator for leaf rust resistance in a compatible interaction between common wheat and Puccinia triticina. Mol. Genet. Genom. 2021, 296, $279-287$. [CrossRef]

26. Zou, S.; Wang, H.; Li, Y.; Kong, Z.; Tang, D. The NB-LRR gene Pm60 confers powdery mildew resistance in wheat. New Phytol. 2018, 218, 298-309. [CrossRef]

27. Chen, D.; Richardson, T.; Chai, S.; Lynne McIntyre, C.; Rae, A.L.; Xue, G.P. Drought-Up-Regulated TaNAC69-1 is a Transcriptional Repressor of TaSHY2 and TaIAA7, and Enhances Root Length and Biomass in Wheat. Plant Cell Physiol. 2016, 57, 2076-2090. [CrossRef]

28. Xue, G.P.; Bower, N.I.; McIntyre, C.L.; Riding, G.A.; Kazan, K.; Shorter, R. TaNAC69 from the NAC superfamily of transcription factors is up-regulated by abiotic stresses in wheat and recognises two consensus DNA-binding sequences. Funct. Plant Biol. 2006, 33, 43-57. [CrossRef]

29. Xue, G.P.; Way, H.M.; Richardson, T.; Drenth, J.; Joyce, P.A.; McIntyre, C.L. Overexpression of TaNAC69 leads to enhanced transcript levels of stress up-regulated genes and dehydration tolerance in bread wheat. Mol. Plant 2011, 4, 697-712. [CrossRef]

30. Huai, B.; Yang, Q.; Qian, Y.; Qian, W.; Kang, Z.; Liu, J. ABA-Induced Sugar Transporter TaSTP6 Promotes Wheat Susceptibility to Stripe Rust. Plant Physiol. 2019, 181, 1328-1343. [CrossRef]

31. Shao, H.; Wang, H.; Tang, X. NAC transcription factors in plant multiple abiotic stress responses: Progress and prospects. Front. Plant Sci. 2015, 6, 902. [CrossRef]

32. Nuruzzaman, M.; Sharoni, A.M.; Kikuchi, S. Roles of NAC transcription factors in the regulation of biotic and abiotic stress responses in plants. Front. Microbiol. 2013, 4, 248. [CrossRef]

33. Zhang, Y.; Geng, H.; Cui, Z.; Wang, H.; Liu, D. Functional Analysis of Wheat NAC Transcription Factor, TaNAC069, in Regulating Resistance of Wheat to Leaf Rust Fungus. Front. Plant Sci. 2021, 12, 604797. [CrossRef]

34. Shen, Q.H.; Saijo, Y.; Mauch, S.; Biskup, C.; Bieri, S.; Keller, B.; Seki, H.; Ulker, B.; Somssich, I.E.; Schulze-Lefert, P. Nuclear activity of MLA immune receptors links isolate-specific and basal disease-resistance responses. Science 2007, 315, 1098-1103. [CrossRef]

35. Chang, C.; Yu, D.; Jiao, J.; Jing, S.; Schulze-Lefert, P.; Shen, Q.H. Barley MLA immune receptors directly interfere with antagonistically acting transcription factors to initiate disease resistance signaling. Plant Cell 2013, 25, 1158-1173. [CrossRef]

36. Du, D.; Zhang, C.; Xing, Y.; Lu, X.; Cai, L.; Yun, H.; Zhang, Q.; Zhang, Y.; Chen, X.; Liu, M.; et al. The CC-NB-LRR OsRLR1 mediates rice disease resistance through interaction with OsWRKY19. Plant Biotechnol. J. 2021, 19, 1052-1064. [CrossRef]

37. Zhang, Y.; Bai, Y.; Wu, G.; Zou, S.; Chen, Y.; Gao, C.; Tang, D. Simultaneous modification of three homoeologs of TaEDR1 by genome editing enhances powdery mildew resistance in wheat. Plant J. 2017, 91, 714-724. [CrossRef]

38. Yan, H.; Zhao, Y.; Shi, H.; Li, J.; Wang, Y.; Tang, D. BRASSINOSTEROID-SIGNALING KINASE1 Phosphorylates MAPKKK5 to Regulate Immunity in Arabidopsis. Plant Physiol. 2018, 176, 2991-3002. [CrossRef]

39. Xu, Q.; Tang, C.; Wang, X.; Sun, S.; Zhao, J.; Kang, Z.; Wang, X. An effector protein of the wheat stripe rust fungus targets chloroplasts and suppresses chloroplast function. Nat. Commun. 2019, 10, 5571. [CrossRef]

40. Chen, Y.; Zhong, G.; Cai, H.; Chen, R.; Liu, N.; Wang, W.; Tang, D. A Truncated TIR-NBS Protein TN10 Pairs with Two Clustered TIR-NBS-LRR Immune Receptors and Contributes to Plant Immunity in Arabidopsis. Int. J. Mol. Sci. 2021, 22, 4004. [CrossRef] 
41. Gao, C.; Sun, P.; Wang, W.; Tang, D. Arabidopsis E3 ligase KEG associates with and ubiquitinates MKK4 and MKK5 to regulate plant immunity. J. Integr. Plant Biol. 2021, 63, 327-339. [CrossRef] [PubMed]

42. Xie, X.B.; Li, S.; Zhang, R.F.; Zhao, J.; Chen, Y.C.; Zhao, Q.; Yao, Y.X.; You, C.X.; Zhang, X.S.; Hao, Y.J. The bHLH transcription factor MdbHLH3 promotes anthocyanin accumulation and fruit colouration in response to low temperature in apples. Plant Cell Environ. 2012, 35, 1884-1897. [CrossRef] [PubMed]

43. Xu, H.; Wang, N.; Liu, J.; Qu, C.; Wang, Y.; Jiang, S.; Lu, N.; Wang, D.; Zhang, Z.; Chen, X. The molecular mechanism underlying anthocyanin metabolism in apple using the MdMYB16 and MdbHLH33 genes. Plant Mol. Biol. 2017, 94, 149-165. [CrossRef] [PubMed]

44. Clough, S.J.; Bent, A.F. Floral dip: A simplified method for Agrobacterium-mediated transformation of Arabidopsis thaliana. Plant J. 1998, 16, 735-743. [CrossRef] [PubMed]

45. Wu, G.; Liu, S.; Zhao, Y.; Wang, W.; Kong, Z.; Tang, D. ENHANCED DISEASE RESISTANCE4 associates with CLATHRIN HEAVY CHAIN2 and modulates plant immunity by regulating relocation of EDR1 in Arabidopsis. Plant Cell 2015, 27, 857-873. [CrossRef] [PubMed] 